\title{
From probabilistic functionalism to a mental simulation of innovation: by collaboration from vulnerabilities to resilient societal systems
}

\author{
Comment on 'Managing complexity: from visual perception to sustainable \\ transitions-contributions of Brunswik's Theory of Probabilistic Functionalism'
}

\author{
Gerald Steiner $^{1}[$ (1)
}

Published online: 16 February 2018

(c) The Author(s) 2018. This article is an open access publication

\begin{abstract}
In this commentary, I build on the Theory of Probabilistic Functionalism by perceptual psychologist Egon Brunswik (190355 ) and Scholz's deepened analysis regarding the implications of this theory for sustainable transition processes by extending these thoughts toward (1) the mental process of simulation of innovation; (2) innovation as a crucial intervention for attaining societal resilience and, hence, an important driver within sustainable transition; and (3) joint representations and collaborative processes for the generation of innovation. By applying the Theory of Probabilistic Functionalism on innovation systems, innovation (as probabilistic entity) is viewed as the object; the agents who initiate or generate the innovation (i.e., entrepreneurs, inventors, innovators, and eventually sustainability planning groups) and the stakeholders who are concerned by the innovation are viewed as the organisms; and the broader innovation system is viewed as the environment. This view aims to provide additional understanding of the complexity and planning of innovation and how it affects and, simultaneously, is affected by society and its environment.
\end{abstract}

Keywords Brunswik's Theory of Probabilistic Functionalism (TPF) $\cdot$ Mental simulation of innovation $\cdot$ Multidimensional innovation · Complexity · Innovation systems · Coupled human-environment systems (HES) · Sustainable transition ·

Societal resilience $\cdot$ Creativity $\cdot$ Collaborative problem solving

\section{Introduction}

In his paper 'Managing complexity: from visual perception to sustainable transitions. Contributions of Brunswik's Theory of Probabilistic Functionalism,' Scholz consolidates Brunswik's fundamental thoughts on the interrelatedness of the organism with the organism's uncertain, probabilistic

This Perspectives paper is a comment on Scholz's "Managing complexity: from visual perception to sustainable transitionscontributions of Brunswik's Theory of Probabilistic Functionalism", Environ Syst Decis. https://doi.org/10.1007/s1066 9-017-9655-4.

Gerald Steiner

gerald.steiner@donau-uni.ac.at

1 Danube Universtiy Krems, Faculty of Business and Globalization, Dr.-Karl-Dorrek-Straße 30, 3500 Krems an der Donau, Austria environment (i.e., probabilistic functionalism). Moreover, Scholz profoundly applies these principles in the context of sustainable transition of coupled human-environment systems (HES) (see also Scholz 2011). Innovation, by taking a forward-thinking perspective (in contrast to an ex post analysis), can be viewed as 'new knowledge' inserted into or originated from a real-world environment and, consequently, is ideally suited for the application of the Theory of Probabilistic Functionalism. The uncertainties and probabilistic nature of innovation, which are almost always embedded in a multidimensional environment, are part of the complex nature of innovation systems. To better understand these specific features in light of Brunswik's Theory of Probabilistic Functionalism (TPF), first, the mental simulation of innovation is discussed based on a differentiation between innovation and invention as two entities with different probabilistic features. Next, some extended thoughts on innovation as potentially crucial intervention for attaining societal 
resilience are outlined. Finally, remarks on joint representations and collaborative processes together with implications for future innovation research conclude the paper.

\section{Mental simulation of innovation in the light of Brunswik}

As basis of this thought experiment, I focus on Brunswik's TPF based on a simplified description of its original core characteristics within visual perception, namely to investigate the ability of people in estimating the size of objects presented to them at varying distances and in different settings (Brunswik 1943, 1952, 1955, 1957). For this, the characteristics of both object and environment-with its overt and covert areas - as well as the relation of both systems need to be taken into account (Brunswik 1957, p 5). Brunswik's TPF extends beyond visual perception and has subsequently also been applied in social judgment theory (e.g., Doherty and Kurz 1996). Following Scholz, a strength of TPF is that it provides a deepened understanding of the interaction of organisms with complex environmental systems. If Brunswik's thoughts on how an organism can acquire a sufficient representation of its complex environment is applied to novel societal developments (i.e., technological but also structural and social innovations as elements of extensive system innovations), it enables to focus on comprehensive environmental cues instead of being constrained by the availability of information (as in many purely deterministic decision experiments). Although the concepts innovation system (e.g., Lundvall 1992) and system innovation (e.g., Elzen et al. 2004) are strongly interlinked, they emphasize different aspects of innovation: Whereas an innovation system describes the learning capabilities and the interlinkage of the various dimensions of human and environment systems in the context of specific learning goals, system innovation as a joint portfolio of various types of innovation stands for the output of an innovation system, which-in the underlying discussion-strives for a sustainable transition of coupled human and environment systems by developing resilient structures and processes.

According to Schumpeter (1934, pp 65-66), innovation and development can be defined as discontinuously evolving 'new combinations of productive means' (i.e., materials and forces), either 'to produce other things, or the same things by a different method.' This is a general and still widely accepted proposition of innovation-based development, which applies to various levels of the societal innovation system and which extends beyond mere products, services, and processes. Whereas the innovation itself is a goal-oriented endeavor with specific outcomes in relation to particular purposes or interests (as a project-like procedure), the innovation system can be understood as its shell, or in other words, as the enabling environment. In general terms, the innovation system (1) goes beyond the single innovation endeavor regarding its aims (e.g., an innovative regional food security system instead of a single fertilizer innovation) and (2) has a more comprehensive time horizon (i.e., beyond that of a single project).

In regard to the origin of innovation, innovation (as the object) may be developed by the organisms (e.g., inventors, innovators, entrepreneurs, but also within stakeholders) either deliberately or coincidentally, or by the environment itself (e.g., as self-organizing processes within complex structures or interlinkages among the single environmental dimensions, underlying drivers, see Fig. 1).

Regarding its field of application, innovation does not merely refer to technological, structural, and social innovation at the organization level, but, at the micro-level, encompasses also citizen-driven innovation, and, at the macro-level, policy innovation as two extremes within the larger societal system (e.g., Steiner et al. 2013, 2014). In the context of its impact, innovation is increasingly viewed as a vehicle toward meta-objectives of a society within a progressively globalized and interlinked world (e.g., Steiner 2014) and part of a future-oriented societal strategy aiming toward sustainable development (e.g., Boons et al. 2013; Cash et al. 2003; Kirschten 2005; Kemp et al. 2007; Provasnek et al. 2016a, b; Smith et al. 2010; Steiner 2009). Hence, the effects of innovation extend far beyond driving competitiveness and are part of a multidimensional innovation system, which itself is an expression of a coupled human-environment system. In that sense and with respect to complex societal real-world problems (e.g., food security, migration movements, social peace), innovation is a prerequisite for the development of resilient societal structures and processes.

Innovation and invention are two interwoven concepts. However, innovation is more far reaching than invention because it implies the application, experiencing (e.g., based on rapid prototyping), and diffusion of new findings (i.e., invention), which may concern the inner system or/and outer system (i.e., environment). For example, as a scientific breakthrough (i.e., invention), Cohen and Boyer's founding discovery for biotechnology (the invention of recombinant DNA technology) in 1973 provided a basis for its subsequent application (i.e., innovation), which led to institutional transformation and the formation of the biotech industry (Cohen et al. 1973; Zucker and Darby 1996). This case also shows how creativity is not only of relevance for (1) gaining new insight, but-with respect to scarce knowledge and often new research techniques-also for (2) finding novel, valuable ways to apply these insights (i.e., inventions) based on mental simulations of potential future fits between a given invention and its environment (i.e., innovation). According to Gilbert and Wilson, 'the brain generates mental simulations (previews) of future events, which produce affective 


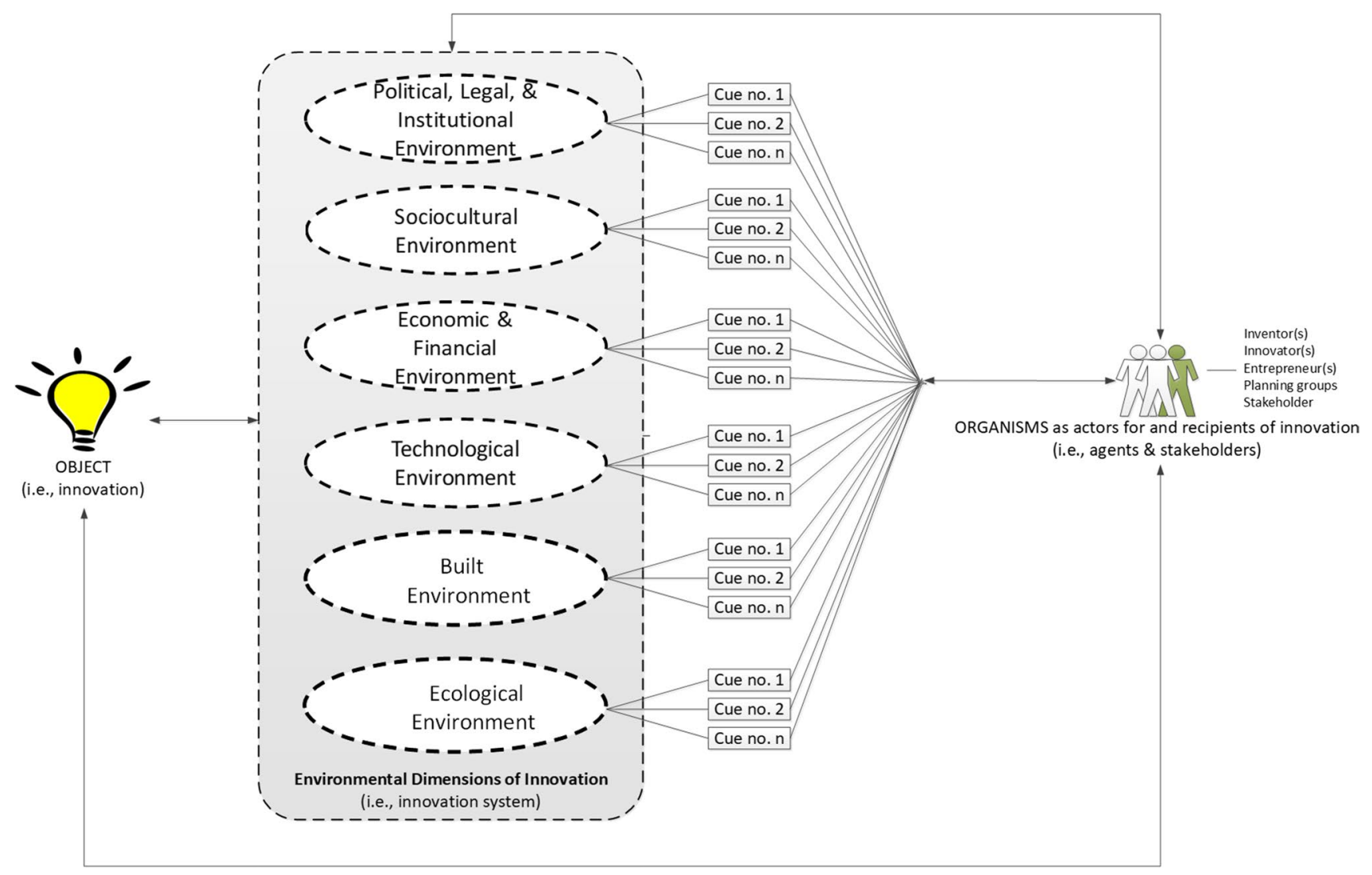

Fig. 1 Mental simulation of innovation: organism (i.e., innovation agents)—object (i.e., innovation)—environment (i.e., innovation system)

reactions (premotions), which are then used as a basis for forecasts (predictions) about the future event's emotional consequences' (Gilbert and Wilson 2009, p 1335). Therefore, specific 'fast and frugal heuristics' can help to order cues by 'evolutionary, social, and individual learning' (Gigerenzer et al. 2008).

Both invention and innovation can be the object of interest within the organism-environment framework, and they can occur as imaginary or physical manifestation (see also Brunswik 1934). However, also a physical manifestation of the invention (e.g., a prototype) or parts of it require a mental simulation with respect to its future market introduction and its potential acceptance among future users (i.e., innovation). Invention can occur in form of a discovery, a new solution to a problem, a scientific breakthrough, or/and a creative accomplishment. If the invention is put into context with its relevant environment (i.e., political, legal, and institutional; sociocultural; economic and financial; technological; built; and ecological dimensions) and agents within these environments (incl. potential future users), it becomes accessible to specific agents of society. By the mechanisms of application and diffusion, the invention can be experienced and has impact on the inner system (e.g., the initial problem) as well as the outer system (e.g., the market), which is called innovation. Hence, accessibility, application, and impact are distinctive features of innovation (which is also the focus in the following) in relation to invention.

Considering TPF and based on a forward-thinking perspective, innovation (as probabilistic entity) is viewed as the object; the agents who initiate or generate the innovation (i.e., entrepreneurs, inventors, innovators, and eventually sustainability planning groups) and the stakeholders who are concerned by the same as the organisms; and the broader innovation system as the environment. As a core mechanism, the concept of 'distance' is related to the mental simulation of innovation as it regards (1) space; (2) time; and (3) the state of the system in dependence of the specific agent or stakeholder position (see the extended arguments below). Consequently, both overt and the covert areas of innovation and of a multidimensional innovation system need to always be considered simultaneously (see Fig. 1).

When visualizing future events within a mental simulation, invention can be imagined as future development (e.g., a novel idea, a solution to a problem or/and a scientific breakthrough) and innovation as the invention applied by certain agents and within specific environmental constellations (see Fig. 1). Hence, the mental simulation of the innovation will lead to affective reactions of the 
visualizing individual. However, these mechanisms are biased because of (1) unstable and uncertain environmental constellations, (2) the reduction in previews to whatat a given moment-is considered the 'essential features,' and (3) truncation (Gilbert and Wilson 2009).

The mental simulation of an innovation, which is not available at the moment yet, will-give or take-impact previous procedures and mechanisms in its domain or field of application, and will significantly differ by the various roles of agents and stakeholders and by their 'distance to the innovation' (see Fig. 1). Whereas the inventor $(s)$ (as part of a collaborative effort) represent the source of the newly acquired knowledge (e.g., invention, scientific breakthrough), it is the role of the innovator(s) as the change agent(s) within such systems, to initiate processes which lead to a novel, valuable application of this knowledge. A specific role can be attributed to entrepreneurs, since they master these application and diffusion processes via the establishment of a viable, newly founded organization (i.e., start-up). Inventors and innovators can theoretically be identical individuals, but might most probably differ because of different competences related to their roles. If stakeholders are integrated in this forward-thinking process (e.g., via scenario analysis and rapid prototyping), their mental simulation on how they will be affected by the innovation might extend the innovators' picture on potential fits or misfits of the innovation in the environmental context. A specific role in the context of sustainable transition may be attributed to the sustainability planning group (which can be understood as an additional but not necessarily mandatory organizational entity for sustainable transition). As a possible extension of agents involved in the generation of innovation, according to Scholz (2017a, b: p 394) the 'sustainability planning group,' is a 'temporary or permanent designated group of members whose task it is to assess critical aspects, develop strategies to overcome barriers, and design future visions, states, and processes for sustaining a (coupled human-environment) system.' With respect to innovation, by providing for a better understanding of future environmental development scenarios in interrelation with specific interventions (i.e., innovation), they need not necessarily be identical with the inventors and innovators, but intensively interact with them. By doing so, they will become enablers of sustainability-oriented innovation, which contributes to the development of resilient societal structures and processes.

Following the principles offered by TPF, the mental simulation of innovation among different agents and stakeholders differs according to their perception of the difference between their own position in relation to the object and the environment. Hence, innovation as the conceived outcome of invention put into context with its environmental systems is perceived with respect to its system characteristics and its interrelations with the environment, or-according to Brunswik - environmental variables might be both 'antecedents and causes of reactions' (Brunswik 1943, p 255).

As a consequence of the coupling mechanisms between the organism (i.e., innovation agents and stakeholders) and the environment (i.e., innovation system), functional adaptations can occur at both the organism and/or the environmental level and might range from incremental to disruptive changes. These coupling mechanisms are expressed also in TPF's complementarity postulate regarding the interrelation of human and environment systems (Scholz 2011, p 31; this is essentially Brunswik's principle P2). Based on this dualistic perspective, innovation can be both (1) an effect of changing environmental systems and (2) a cause of changes in the environments.

Hence, change will originate from either (1) the environment (e.g., sociocultural, economic, legislative, technological, or ecological dimensions), (2) the organism (innovation agents and stakeholders), or (3) the dualistic interaction of both entities, where the object (i.e., the innovation) is a means of reactive or proactive adaption. The perception of a necessity to invest mental resources for innovation, and the thinking process about the extent and pace of adaptation, will both depend on the position and capability of the organism in relation to its environment (which includes the position of the organism in relation to other innovation generating entities). For example, two organizations A and B, both within the same industrial field, will perform differently regarding their innovation capabilities and they will have different mental simulations of innovation in dependence of their respective positions to the environment (either regarding space, time, and state of the system): An organization A, which proactively innovates at a high pace and extent, will, consequently, exhibit high adaptation capabilities, which might also be coupled and triggered by positive affective reactions (premotions). In contrast, organization $\mathrm{B}$, which at its best reactively innovates, to a lower extent and at a low pace, might consider a similar innovation pattern differently, more impressive and groundbreaking than the proactively innovating organization. Similar to Brunswik, position and setting do matter and might even be responsible for a constructive versus a destructive effect of the change, which might be initiated by either the environment or the object.

\section{Innovation as crucial intervention for attaining societal resilience}

Generally speaking, an understanding of the interrelation between organisms (i.e., the subject's or organizations' invention) and environment as coupled systems in the context of their development over time (i.e., in relation to different future scenarios) is a precondition for being able to 
reflect on inherent vulnerabilities and opportunities that might be related to organisms, the environment, or their interrelatedness. As stated by Lenski et al. (1991), the potential improvement of personal living conditions (i.e., the interrelation between organism/subject and environment) becomes the driver for attempts to develop new technologies (i.e., innovations). Therefore, innovation is not only critical for national growth rates but also for the viability and competitiveness of societal systems of various scopes, ranging from organizational to meta-national innovation systems (Steiner 2014).

As a special case, digitalization provides evidence that technological change needs to be analyzed not only with respect to new business opportunities but also with respect to potential vulnerabilities (Scholz 2017a, b). Regarding the development of resilient societal structures and processes, digitalization and its effects on coupled human-environment systems needs to be analyzed and understood in conjunction with its main system mechanisms as a basis for the effects, which specific interventions might have on potential scenario developments. The specific case of digitalization demonstrates that the development of new technologies might improve the living conditions of group X (e.g., leading to an increase in their wealth and power) while being destructive for the living conditions of group Y. If group X and $\mathrm{Y}$ are symbiotically interrelated, this feedback mechanism might ultimately be destructive for society and its viability. The challenge for the development of innovation, which is supportive for a resilient society and for sustainable development, is to set system boundaries appropriately, i.e., by avoiding setting those too narrowly. Consequently, resilience management is an endeavor, which goes beyond risk management by 'integrating the temporal capacity of a system to absorb and recover form adverse events and to adapt' (Linkov et al. 2014, p 407). In this line, resilience management needs to address the complexity of coupled and integrated systems, the uncertainty of future treats and vulnerabilities in addition to potential opportunities, together with its dynamically evolving innovation capacities.

Consequently, although the creation of innovation is not necessarily related to a thorough understanding of the system's mechanisms described above, innovation and innovative thinking is a prerequisite for the development of resilient societal structures and processes (e.g., Linkov et al. 2014, p 408; Scholz et al. 2017). For example, the development and application of technology such as the atomic bomb showed a high degree of innovativeness and creativity, but it lacked the 'wisdom' to prevent destruction by preventing its application. To be more specific, nuclear research in its beginnings required a mixture of curiosity, scientific rigor, and rationality, creativity, and ingenuity. Further, the application and translation of newly gained knowledge into ideas, for example to consider nuclear energy as a sustainable energy form, which could help to reduce carbon, was initially a promising possibility for future energy policies. However, subsequently occurring disturbances, e.g., several nuclear disasters, point at the misinterpretation of the perceived possibilities of this technology. By contrast, the Manhattan Project was from the very first beginning a planned innovation with purely destructive effects. Hence, innovations and underlying processes need to be embedded within a goaland value-based framework such as provided by a human rights Charta or goals related to sustainable development.

\section{Joint representations and collaborative processes}

Societal challenges are mostly of complex nature and affect various agents in the multilayered societal system, ranging from the individual to groups, nations, continents, regions, and the global society. As already stressed by Schumpeter (1934), innovation needs also to be associated with 'creative destruction,' i.e., while some stakeholders will be better off due to the implementation of a given innovation, others will be worse off because of the 'destruction' or replacement of previous approaches and technologies (see also Sect. 2).

With respect to a sustainable transition path (as suggested in this manuscript), an extended picture of the constellation and operation of planning groups, together with-and in contrast to-innovation groups, is essential. The specific aim of a planning group is to understand, reflect, and intervene within the transition process based on the identification of (obvious and hidden) vulnerabilities and opportunities within the own system or/and its environment. By contrast, an innovation group aims to generate innovations that lead to system improvements based on new ideas and technologies, with respect to single or multiple dimensions (e.g., efficiency improvements, increased output, decreased ecological or social burdens), which are not at the disposal of decision makers, planning groups, etc. The argument is that the planning and understanding of complex real-world problems stresses different competences compared to creatively imagining and inventing solutions, which introduce new technologies, mechanisms, processes, etc., to a certain system with respect to particular aims. This may include personal, professional domain, systemic, creativity, and sociocultural competences (Steiner 2013, 2014; Steiner et al. 2013, 2014). Within their working procedures (either as one identical or two different groups), both groups might follow a transdisciplinary process as a form of cooperation between science and society based on principles such as mutual learning and co-leadership (as suggested by, e.g., Scholz and Steiner 2015).

With respect to what Brunswik calls 'covert areas' (Brunswik 1957, p 5), an extended differentiation between 
a person's explicitly self-reported and implicit attitudes (Steiner et al. 2018) could lead to a supportive differentiation, particularly regarding development paths related to sustainable transition processes and the specific role that planning and innovation groups play within these processes. Although planning and innovation groups are each specific forms of collaboration, the awareness of their specifics (e.g., regarding purpose, team constellation, working processes, and implicit versus explicit attitudes) together with the acknowledgement of synergies is beneficial for a comprehensive transition process, which is aimed to enable and establish resilient processes and structures by means of innovation.

For innovation, curiosity and creative problem solving most often extends beyond individuals and requires group effort based on specific competence portfolios. Collaborative problem solving needs to be based on joint system representations (i.e., shared mental models or cognitive maps), which might also require to initially discover the underlying problems within them (Steiner 2014).

\section{TPF's implications for future innovation research}

Based on the general and fundamental implications of Brunswik's TPF on the transition of societal systems as stressed by Scholz, it particularly shows to have an influence on comprehensive (societal) innovation systems. Multidimensional innovation systems are an expression of coupled human-environment systems and the duality of their effect mechanisms: On the one hand, they are influenced by environmental change stimuli; on the other hand, they are drivers of societal change. This shows tremendous potential for the application of Brunswik's principles on the understanding of the effects of innovations on various stakeholders (e.g., Provasnek et al. 2016a, b), subsystems, and the environmental systems. Hence, I imagine various fields of application, which include:

1. The analysis of multidimensional innovation systems in the context of multilayered societal systems (i.e., coupled multilayered innovation systems).

2. Implicit and explicit attitudes of involved agents and affected stakeholders of the single subsystems.

3. Transdisciplinary cooperation in the sense of sciencesociety collaboration for an elaborated understanding of complex societal challenges and related changes (e.g., migration, climate change, food security, health, economic crises, technological change such as digitalization, globalization) and derived policy implications in the context of collaboratively developed future scenarios.

All these fields of application have in common that they depend on processes, which provide reliable judgment related to complex challenges that are characterized by uncertainty and dynamic developments instead of deterministic patterns. TPF is related to the challenges described above and opens the floor for necessary cross-boundary collaborations, as expressed in transdisciplinary cooperation between science and society.

Acknowledgements Open access funding provided by Danube University Krems University for Continuing Education.

Open Access This article is distributed under the terms of the Creative Commons Attribution 4.0 International License (http://creativeco mmons.org/licenses/by/4.0/), which permits unrestricted use, distribution, and reproduction in any medium, provided you give appropriate credit to the original author(s) and the source, provide a link to the Creative Commons license, and indicate if changes were made.

\section{References}

Boons F, Montalvo C, Quist J, Wagner M (2013) Sustainable innovation, business models and economic performance: an overview. J Clean Prod 45:1-8

Brunswik E (1934) Wahrnehmung und Gegenstandswelt: Grundlegung einer Psychologie vom Gegenstand her. Deuticke, Leipzig

Brunswik E (1943) Organismic achievement and environmental probability. Psychol Rev 50:255-272

Brunswik E (1952) The conceptual framework of psychology. University of Chicago Press, Chicago

Brunswik E (1955) Representative design and probabilistic theory in a functional psychology. Psychol Rev 62:193-217

Brunswik E (1957) Scope and aspects of the cognitive problem. In: Gruber H, Hammond KR, Jessor R (eds) Contemporary approaches to cognition. Harvard University Press, Cambridge, pp 41-69

Cash DW, Clark WC, Alcock F, Dickson NM, Eckley N, Gutson DH, Jager J, Mitchell RB (2003) Knowledge systems for sustainable development. Proc Natl Acad Sci USA 100:8086-8091

Cohen S, Chang A, Boyer H, Helling R (1973) Construction of biologically functional bacterial plasmids in vitro. Proc Natl Acad Sci USA 70:3240-3244

Doherty ME, Kurz ME (1996) Social judgement theory. Think Reason 2:109-140

Elzen B, Geels FW, Green K (2004) System innovation and the transition to sustainability: theory, evidence and policy. Edward Elgar Publishing, Cheltenham

Gigerenzer G, Hoffrage U, Goldstein D (2008) Fast and frugal heuristics are plausible models of cognition: reply to Dougherty, FrancoWatkins, and Thomas (2008). Psychol Rev 115:230-239

Gilbert DT, Wilson TD (2009) Why the brain talks to itself: sources of error in emotional prediction. Philos Trans R Soc B 364:1335-1341

Kemp R, Loorbach D, Rotmans J (2007) Transition management as a model for managing processes of co-evolution towards sustainable development. Int J Sustain Dev World Ecol 14:78-91 
Kirschten U (2005) Sustainable innovation networks: conceptual framework for institutionalization. Prog Ind Ecol 2:132-147

Lenski G, Lenski J, Nolan P (1991) Human societies. An introduction to macrosociology. McGraw-Hill, New York

Linkov I et al (2014) Changing the resilience paradigm. Nat Clim Change 4:407-409. https://doi.org/10.1038/nclimate2227

Lundvall B-A (1992) National systems of innovation: towards a theory of innovation and interactive learning. Pinter Publishers, London

Provasnek A, Geissler B, Schmid E, Steiner G (2016a) Sustainable corporate entrepreneurship: performance and strategies toward innovation. Bus Strategy Environ 26:521-535. https://doi.org/10.1002/ bse. 1934

Provasnek A, Schmid E, Steiner G (2016b) Stakeholder engagement: keeping business legitimate in Austria's natural mineral-water bottling industry. J Bus Ethics. https://doi.org/10.1007/s1055 1-016-3121-y

Scholz RW (2011) Environmental literacy in science and society: from knowledge to decisions. Cambridge University Press, Cambridge

Scholz RW (2017a) Digital threat and vulnerability management: the SVIDT method. Sustainability 9:554. https://doi.org/10.3390/ su9040554

Scholz RW (2017b) Managing complexity: from visual perception to sustainable transitions - contributions of Brunswik's Theory of Probabilistic Functionalism. Environ Syst Decis 37:381-409. https://doi.org/10.1007/s10669-017-9655-4

Scholz RW, Steiner G (2015) The real type and the ideal type of transdisciplinary processes. Part I-theoretical foundations. Sustain Sci 10:527-544. https://doi.org/10.1007/s11625-015-0326-4

Scholz RW, Yarime M, Shiroyama H (2017) Global leadership for social design: theoretical and educational perspectives. Sustan Sci. https://doi.org/10.1007/s11625-017-0454-0
Schumpeter JA (1934) The theory of economic development. An inquiry into profits, capital, credit, interest, and the business cycle. Harvard University Press, Cambridge

Smith A, Voss JP, Grin J (2010) Innovation studies and sustainability transitions: the allure of multilevel perspective and its challenges. Res Policy 39:435-448

Steiner G (2009) The concept of open creativity: collaborative creative problem solving for innovation generation-a systems approach. J Bus Manag 15:5-34

Steiner G (2013) Competences for complex real-world problems: toward an integrative framework. Working paper 2013-0002, Weatherhead Center for International Affairs, Harvard University

Steiner G (2014) Problem discovery as a collaborative, creative, and method-guided search for the "real problems" as raw diamonds of innovation. Working paper 2014-0003, Weatherhead Center for International Affairs, Harvard University

Steiner G, Risopoulos F, Mulej M (2013) Competences for citizendriven innovation in crisis resolution. Syst Pract Act Res 26:571577. https://doi.org/10.1007/s11213-013-9307-7

Steiner G, Risopoulos F, Mulej M (2014) Social responsibility and citizen-driven innovation in sustainably mastering global socioeconomic crises. Syst Res Behav Sci 32:160-167. https://doi. org/10.1002/sres.2255

Steiner G, Geissler B, Schreder G, Zenk L (2018) Living sustainability or pretending to? From explicit self-report measures to implicit cognition. Sustain Sci (under review)

Zucker LG, Darby MR (1996) Star scientists and institutional transformation: patterns of invention and innovation in the formation of the biotechnology industry. Proc Natl Acad Sci USA 93:1270912716. https://doi.org/10.1073/pnas.93.23.12709 